\title{
Short communication: Genomic selection for hoof lesions in first-parity US Holsteins
}

\author{
K. Dhakal, ${ }^{* 1}$ F. Tiezzi, ${ }^{*}$ J. S. Clay, $†$ and C. Maltecca* \\ *Department of Animal Science, North Carolina State University, Raleigh 27695 \\ †Dairy Records Management Systems, Raleigh, NC 27603
}

\begin{abstract}
Hoof lesions contributing to lameness are crucial economic factors that hinder the profitability of dairy enterprises. Producer-recorded hoof lesions data of US Holsteins were categorized into infectious (abscess, digital and interdigital dermatitis, heel erosion, and foot rot) and noninfectious (korn, corkscrew, sole and toe ulcer, sole hemorrhage, white line separation, fissures, thin soles, and upper leg lesions) categories of hoof lesions. Pedigree- and genomic-based univariate analyses were conducted to estimate the variance components and heritability of infectious and noninfectious hoof lesions. A threshold sire model was used with fixed effects of year-seasons and random effects of herd and sire. For genomic-based analysis, a single-step procedure was conducted, incorporating $\mathbf{H}$ matrix to estimate genomic variance components and heritability for hoof lesions. The pedigree-based analysis produced heritability estimates of $0.11( \pm 0.05)$ for infectious hoof lesions and $0.08( \pm 0.05)$ for noninfectious hoof lesions. The single-step genomic analysis produced heritability estimates of $0.14( \pm 0.06)$ for infectious hoof lesions and $0.12( \pm 0.08)$ for noninfectious hoof lesions. Approximated genetic correlations between hoof lesion traits and hoof type traits along with productive life and net merit were all low and ranged between -0.25 and 0.14 . Sire reliabilities increased, on average, by 0.24 and 0.18 for infectious and noninfectious hoof lesions, respectively, with incorporation of genomic data.
\end{abstract}

Key words: genomic selection, hoof lesions, reliability

\section{Short Communication}

Hoof lesions are a primary cause of lameness in most dairy herds (Oberbauer et al., 2013). Lameness is recognized as a major cause of economic loss in the dairy

Received September 8, 2014.

Accepted January 13, 2015.

${ }^{1}$ Corresponding author: kdhakal@ncsu.edu industry due to its unfavorable effect on productivity and profitability in commercial dairy operations (Hernandez et al., 2005; Bicalho and Oikonomou, 2013). Lameness causes pain, leading to a debilitating condition and distress in affected cows, which is considered a serious animal welfare issue (Vermunt, 2007; von Keyserlingk et al., 2009). A few decades ago, the incidence of lameness in dairy cattle in the United States was estimated at $15 \%$ (Wells et al., 1993), and a more recent study in 3 commercial California dairies performed by Oberbauer et al. (2013) reported that the prevalence of hoof lesions ranged from $2.2 \%$ (foot rot) to $17.1 \%$ (digital dermatitis). Guard (1999) estimated direct cost due to lameness in a 100 -cow herd to be $\$ 7,600$.

Genomic selection in dairy cattle breeding showed greater accuracy of predicted genetic merit for young bulls (Hayes et al., 2009; VanRaden et al., 2009). Improving health traits of dairy cattle using genomic selection is appealing. Research on hoof lesions has recently started in the United States (Parker Gaddis et al., 2012, 2014). Parker Gaddis et al. (2014) estimated genomic variance components and heritabilities for various health events using producer-recorded health data. Several previous studies have reported the heritabilities of hoof lesions using pedigree relationship matrix (Buch et al., 2011; Chapinal et al., 2013). However, previous studies have not evaluated specific categories of hoof lesions using genomic information. The objectives of the current study were to (1) estimate the genomic variance components and heritability of hoof lesions in US Holsteins, (2) compare the sire PTA reliabilities between pedigree- and genomic-based analyses, and (3) compare the genetic association between hoof lesions data coming from different sources and recorded in different formats.

Information used in this study was obtained from 3 sources. Two data sets were provided by Dairy Records Management Systems (Raleigh, NC) and were collected on US Holstein cows from 2007 to 2013. The hoof lesions data set $(\boldsymbol{H O O F})$ contained specific records for hoof lesions (e.g., abscess, heel erosion, sole ulcer) that were recorded by trained dairy farmers and hoof trimmers. The lameness data set $(\boldsymbol{L} \boldsymbol{A} \boldsymbol{M E})$ contained 
data that were recorded for the same period as a single category (presence or absence of lameness) and were recorded by farmers using on-farm software as part of the routine management. Hoof-health related information collected from on-farm data is sometime criticized for not providing a reliable measure of the true occurrence of hoof lesions. Therefore, the 2 sets of data, $H O O F$ and $L A M E$, allowed a direct comparison of the measure used and were considered different traits. The third data set included type traits information and was obtained from Holstein Association USA (Brattleboro, VT).

In both $H O O F$ and $L A M E$ data sets, records on firstparity Holstein cows were retained and subjected to a series of data quality edits following Parker Gaddis et al. (2012). This included imposing minimum and maximum constraints on that data by herd to avoid herds that either over- or under-represented hoof lesion or lameness events. Furthermore, sires with fewer than 3 daughters were removed. Editing reduced the $H O O F$ data set from 36,672 , to 23,467 first-parity records. Hoof lesions were recorded in a binary format: "0" was assigned to healthy cows and "1" was assigned to cows that presented at least one hoof lesion. Multiple lesions were infrequent $(<6 \%)$ and were coded as a single occurrence. Hoof lesions were categorized into 2 different traits: infectious and noninfectious hoof lesions. Hoof lesions grouped under infectious hoof lesions included abscess, digital and interdigital dermatitis, heel erosion, and foot rot lesions. Similarly, hoof lesions categorized under noninfectious hoof lesions included korn, corkscrew, sole and toe ulcer, sole hemorrhage, white line separation, fissures, thin soles, and upper leg lesions. The LAME data set contained 87,471 records after applying data quality edits. Lameness was again coded as "0" for healthy cows and " 1 " for cows with at least one lameness recording. The HOOF and LAME data sets were further combined. Records retained included phenotypes from both sources $(\mathrm{n}=12,881)$ as well as records that were missing either hoof lesion $(\mathrm{n}=$ $20,660)$ or lameness $(\mathrm{n}=74,590)$ information. The latter were assigned a missing value for the missing trait. The combined data set was termed HOOF-LAME and included 108,131 records.

Pedigree and genomic-based analyses were performed for each hoof lesion category (infectious and noninfectious) using the HOOF data set. A threshold sire model was used to estimate pedigree-based variance components and heritability using the THRSGIBBS1F90 program (version 2.104; Tsuruta and Misztal, 2006). The model was

$$
\lambda=\mathbf{X} \boldsymbol{\beta}+\mathbf{Z}_{\mathbf{h}} h+\mathbf{Z}_{\mathrm{s}} s+\mathbf{e},
$$

where $\boldsymbol{\lambda}$ represents a vector of unobserved liabilities to the given hoof lesion; $\boldsymbol{\beta}$ is a vector of fixed effects including overall mean and year-season; $h$ represents the random herd effect, where $h \sim N\left(0, \mathbf{I} \sigma_{h}^{2}\right)$, with $\mathbf{I}$ representing an identity matrix and $\sigma_{h}^{2}$ representing the variance of herd; $s$ represents the random sire effect, where $s \sim N\left(0, \mathbf{A} \sigma_{s}^{2}\right)$, with $\mathbf{A}$ representing the additive genetic relationship matrix and $\sigma_{s}^{2}$ representing the sire variance; $\mathbf{X}$ represents the corresponding incidence matrix for the fixed effect; $\mathbf{Z}_{\mathrm{h}}$ and $\mathbf{Z}_{\mathrm{s}}$ represent the corresponding incidence matrices for the appropriate random effects; and e represents the random residuals following $N(0, \mathbf{I})$ and fixing the variance equal to 1 to attain identifiability.

For the genomic analysis, the preGSf90 software (version 1.142; Aguilar et al., 2011) was used to incorporate genomic data into the blended $\mathbf{H}$ matrix in a singlestep procedure (Aguilar et al., 2010; Legarra and Ducrocq, 2012). The $\mathbf{H}$ matrix was used in lieu of $\mathbf{A}$ for the random sire effect $s \sim N\left(0, \mathbf{H} \sigma_{s}^{2}\right)$. Quality control of the genomic data was performed using default settings of the preGSf90 software. These included exclusion of SNP located in the sex chromosome, SNP having minor allele frequency of $<0.05$, and SNP with call rates below 0.90 . In addition, quality control included removal of individuals with a call rate below 0.90. After applying data quality edits, genomic data were available on 40,608 markers for 471 sires. The average number of daughters per sire was 28 (maximum $=362$, minimum $=3$ ). The $\mathbf{G}$ matrix was calculated following VanRaden (2008), using allele frequencies calculated from the available genotypes.

A Monte Carlo Markov chain approach through Gibbs sampling was used to obtain estimates of variance components. In total, 300,000 iterations were completed, with the first 50,000 discarded as burn-in and storing every 100th sample. Convergence was assessed by visual inspection of trace plots, and additional diagnostic tests were carried out to confirm convergence such as obtaining estimates of autocorrelation and effective sample size through R (http://cran.r-project.org) with the CODA package (Plummer et al., 2013). Post-Gibbs analyses were completed using the POSTGIBBSF90 program (version 3.04; Misztal et al., 2002).

Reliabilities were obtained with both pedigree and genomic information to assess the advantage of including the latter information in the analysis. To do so, we relaxed the editing constraint on the number of daughters per sires. We therefore included sires with fewer than 3 progenies in an additional analysis in which sire variance was fixed at the estimate obtained with the constraint in place. Approximate reliabilities 
Table 1. Posterior mean, SD, and 95\% highest posterior density (HPD) of variance components and heritability of infectious and noninfectious hoof lesions obtained from pedigree- and genomic-based analysis

\begin{tabular}{|c|c|c|c|c|c|c|c|c|c|}
\hline \multirow[b]{2}{*}{ Trait } & \multicolumn{3}{|c|}{ Sire variance } & \multicolumn{3}{|c|}{ Herd variance } & \multicolumn{3}{|c|}{ Heritability } \\
\hline & Mean & $\mathrm{SD}$ & $95 \% \mathrm{HPD}$ & Mean & SD & $95 \% \mathrm{HPD}$ & Mean & $\mathrm{SD}$ & $95 \%$ HPD \\
\hline Infectious & 0.039 & 0.017 & {$[0.008 ; 0.071]$} & 0.325 & 0.066 & {$[0.209 ; 0.462]$} & 0.113 & 0.047 & {$[0.024 ; 0.202]$} \\
\hline Noninfectious & 0.027 & 0.018 & {$[0.001 ; 0.063]$} & 0.344 & 0.077 & {$[0.206 ; 0.500]$} & 0.077 & 0.052 & {$[0.001 ; 0.179]$} \\
\hline \multicolumn{10}{|l|}{ Genomic-based } \\
\hline Infectious & 0.048 & 0.022 & {$[0.008 ; 0.092]$} & 0.325 & 0.066 & {$[0.209 ; 0.457]$} & 0.138 & 0.063 & {$[0.021 ; 0.257]$} \\
\hline
\end{tabular}

of pedigree PTA were calculated using the ACCF90 program (version 1.67; Misztal et al., 2002). Similarly, reliabilities of genomic PTA were approximated following Misztal et al. (2013).

Genetic correlations between each hoof lesion and hoof type traits, such as feet and leg (FL), rear leg set (RLS), foot angle (FANG), and rear leg rear view (RLRV), along with productive life (PL), and net merit (NM), were approximated using the reliabilities of sire PTA following Calo et al. (1973). The PL and NM sire PTA were obtained from the national genetic evaluation system (Cole and VanRaden, 2010). For the hoof type traits, data were available for only 206 sires. For breeding purposes, negative genetic correlations between hoof lesion and hoof type traits are favorable.

Correlations between each hoof lesion category and the lame trait were obtained from a series of pedigree- and genomic-based bivariate analyses using the HOOF-LAME data set. Fixed and random effects were identical to those described in the univariate analyses.

Frequencies of infectious and noninfectious hoof lesions were 2.27 and $2.08 \%$, respectively. Chapinal et al. (2013) reported the incidence rates of front and rear hoof lesions in first-parity cows. The front hoof lesion incidence rates were $2.7,4.4$, and $0.9 \%$ for infectious, horn, and other hoof lesions, respectively. Similarly, the rear hoof lesion incidence rates were 23.8, 13.1, and $2.9 \%$ for infectious, horn, and other hoof lesions, respectively. Infectious hoof lesions were the more common hoof lesions in our study, in agreement with other studies that classified lesions similarly (Somers et al., 2003; Holzhauer et al., 2006; Chapinal et al., 2013).

Posterior means of pedigree- and genomic-based variance components and heritability of infectious and noninfectious hoof lesions are shown in Table 1. As expected, sire variance components increased in genomicbased analysis compared with pedigree-based analysis, resulting in slightly higher heritability of hoof lesions. The genomic relationships between sires may have captured the actual variation introduced by chromosomal segregation. The heritability estimates of infectious hoof lesions from pedigree- and genomic-based analyses were $0.11( \pm 0.05)$ and $0.13( \pm 0.06)$ respectively. Similarly, the heritability estimates of noninfectious hoof lesions from pedigree- and genomic-based analysis were $0.08( \pm 0.05)$ and $0.12( \pm 0.08)$ respectively. The differences in heritability estimates between pedigree- and genomic-based analyses may be due to the differences in scale of the relationship matrices and because different base populations were used in creating the $\mathbf{A}$ and $\mathbf{H}$ matrices (Parker Gaddis et al., 2014). The heritability estimates for infectious hoof lesions were in agreement with those of a previous study conducted by Chapinal et al. (2013). Johansson et al. (2011) reported similar heritability estimates of infectious hoof lesions from the study conducted in Holstein populations of Finland and Sweden. It should be noted that, most of the time, etiology remains unknown for noninfectious hoof lesions and thus genetic variance obtained for noninfectious lesions may not reflect true genetic variance.

The comparison between sire PTA reliabilities from pedigree- and genomic-based is shown in Table 2. The addition of genomic data improved reliabilities for both infectious and noninfectious hoof lesions. The average increment in reliability using genomic data was 0.24 and 0.18 for infectious and noninfectious hoof lesions, respectively. For infectious hoof lesions, the sire PTA reliabilities ranged from 0.26 to 0.64 and that of sire genomic PTA from 0.32 to 0.81 . For noninfectious hoof lesions, the sire PTA reliability range was from 0.24 to 0.58 and that of sire genomic PTA reliability from 0.29 to 0.74 . The sires' gain in reliability obtained with the

Table 2. Comparison of mean reliabilities of PTA and genomic PTA (GPTA) from pedigree- and genomic-based analysis

\begin{tabular}{lccc}
\hline Trait & $\begin{array}{c}\text { PTA } \\
\text { reliability }\end{array}$ & $\begin{array}{c}\text { GPTA } \\
\text { reliability }\end{array}$ & $\begin{array}{c}\text { Overall } \\
\text { gain }^{1}\end{array}$ \\
\hline Infectious & 0.42 & 0.66 & 0.24 \\
Noninfectious & 0.30 & 0.48 & 0.18 \\
\hline
\end{tabular}

${ }^{1}$ Gain in reliability due to difference between reliability obtained from pedigree- and genomic-based analysis. 
A

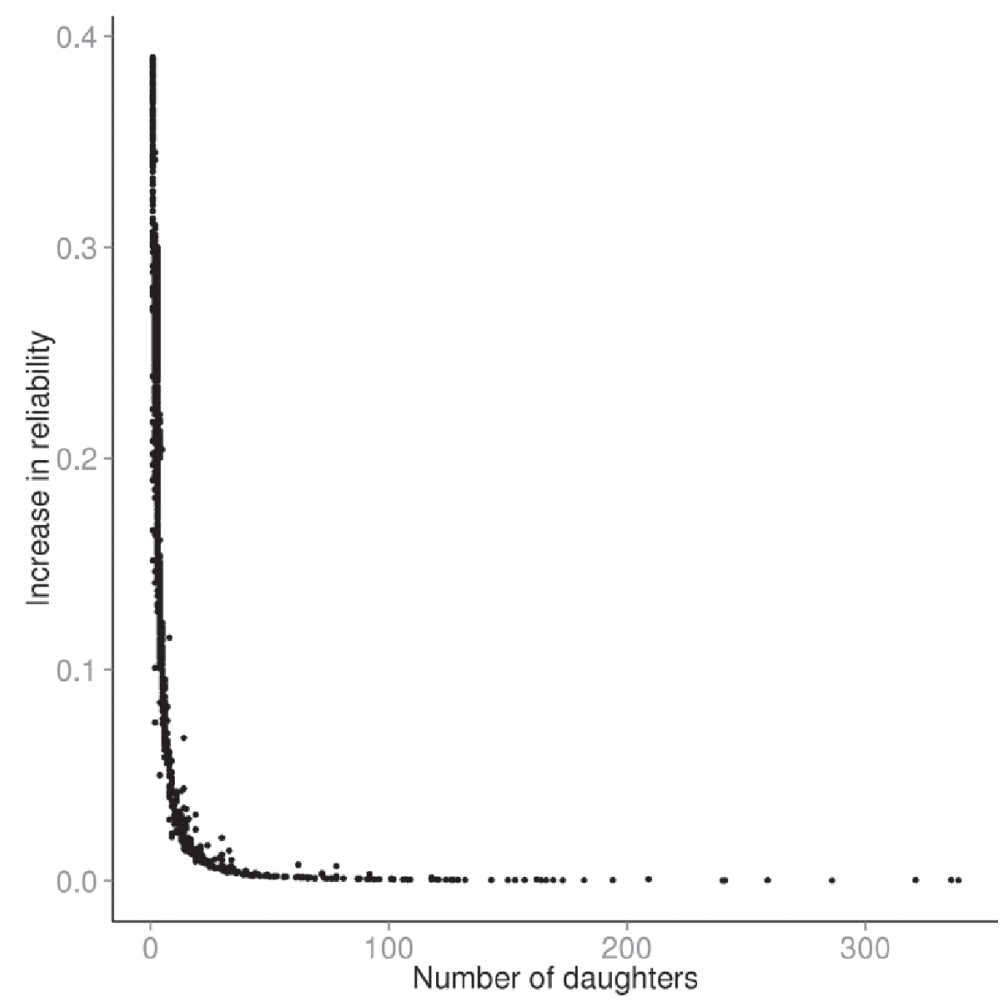

B

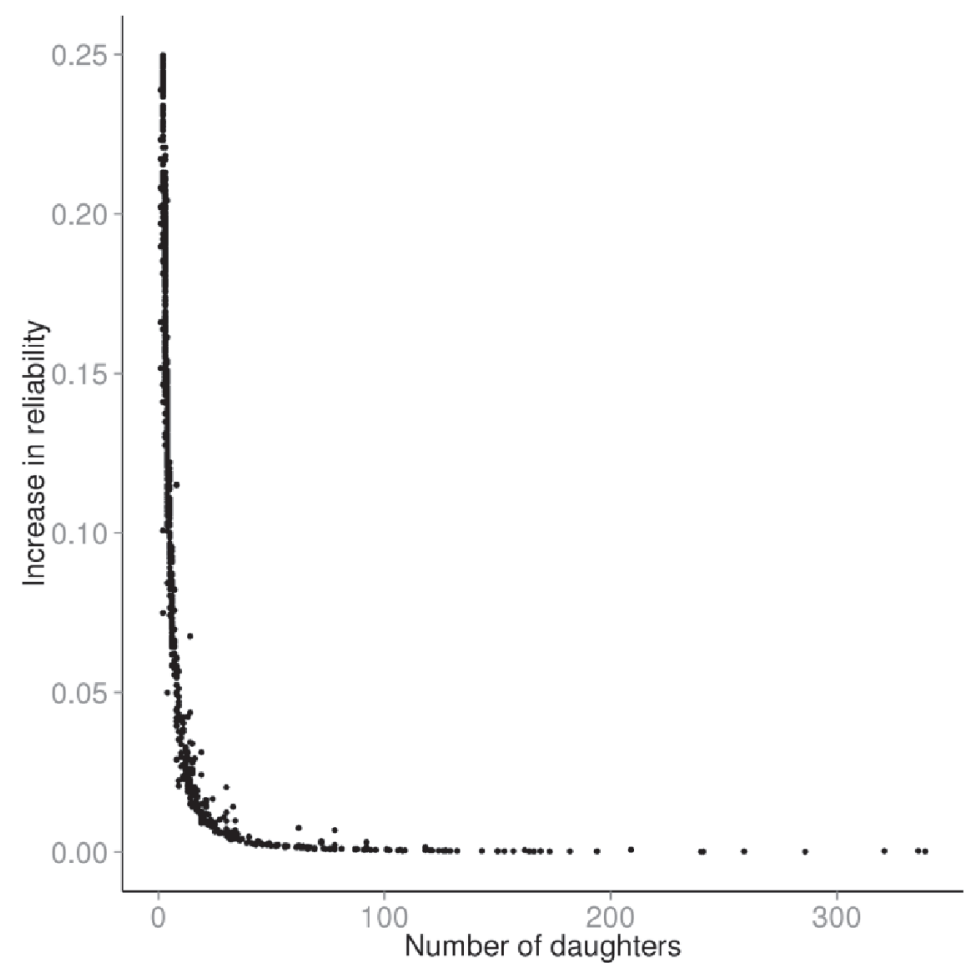

Figure 1. Increase in reliability trend with respect to number of daughters per sire in univariate single-step analysis for (A) infectious hoof lesions and (B) noninfectious hoof lesions. Color version available online. 
Table 3. Approximated genetic correlations (SE in parentheses) between hoof type traits, productive life, and net merit with results from pedigree-based analysis

\begin{tabular}{|c|c|c|}
\hline \multirow[b]{2}{*}{ Trait } & \multicolumn{2}{|c|}{ Hoof lesions } \\
\hline & Infectious & Noninfectious \\
\hline Feet and $\operatorname{leg}^{1}$ & $-0.06(0.029)^{*}$ & $0.02(0.028)$ \\
\hline Rear leg set ${ }^{1}$ & $0.14(0.026)^{*}$ & $0.13(0.024)^{*}$ \\
\hline Foot angle ${ }^{1}$ & $-0.04(0.029)$ & $0.10(0.027)^{*}$ \\
\hline Rear leg rear view ${ }^{1}$ & $-0.25(0.032)^{*}$ & $-0.09(0.030)^{*}$ \\
\hline Productive life & $-0.03(0.014)^{*}$ & $0.05(0.013)^{*}$ \\
\hline Net merit & $-0.08(0.014)^{*}$ & $-0.02(0.012)$ \\
\hline
\end{tabular}

${ }^{1}$ Hoof type traits.

* Genetic correlation significant at $P<0.05$.

inclusion of genomic information for increasing number of progeny is depicted in Figure $1 \mathrm{~A}$ and $\mathrm{B}$ for infectious and noninfectious hoof lesions, respectively. As expected, the use of genomic data improved mainly the reliabilities of young sires with few or no daughters.

Sire PTA reliabilities for hoof type traits ranged from 0.11 to 0.19 . Approximate genetic correlations between hoof lesions and hoof type traits along with PL and NM are shown in Table 3 . All correlations were significant $(P<0.05)$ when the $t$-test was used (Campbell and Machin, 1999) except for those between FANG and infectious hoof lesions, FL and noninfectious hoof lesions, and NM and noninfectious hoof lesions. Negative genetic correlations were observed for infectious hoof lesions with all traits except for RLS, indicating that increased genetic liability to infectious hoof lesions is associated with decreased PL, NM, and hoof type traits. Ødegård et al. (2014) reported a negative genetic correlation between infectious hoof lesions and RLRV in their study on Norwegian Red cows. In case of noninfectious hoof lesion, only RLRV and NM traits were negatively correlated. Gernand et al. (2013) reported that RLRV was negatively correlated with sole ulcer. Based on the observations, it can be inferred that hoof type traits could be used for genetic selection for infectious hoof lesions in situations where hoof lesions phenotype are difficult to record.

The posterior means, standard deviations, and 95\% highest posterior density (HPD) of pedigree- and genomic-based heritabilities and genetic correlations from bivariate analyses are shown in Table 4. Bivariate analyses showed higher heritabilities than the corresponding univariate analyses. Moreover, genomic-based analyses resulted in higher heritabilities than pedigreebased analyses. Genomic information contained in the $\mathbf{H}$ matrix allows consideration of Mendelian sampling for genotype individuals into the additive genetic effect, leading to higher variance estimates. Heritability estimates were $0.11( \pm 0.05), 0.10( \pm 0.05)$, and 0.04 $( \pm 0.01)$, for infectious, noninfectious, and lameness traits, respectively, in pedigree-based analysis, whereas in genomic-based analysis, heritability estimates were $0.17( \pm 0.07), 0.15( \pm 0.07), 0.06( \pm 0.02)$, for infectious, noninfectious, and lameness traits, respectively. Most of the previous studies categorized all hoof lesions into a single lameness event. Heritability of lameness has been estimated between 0.02 and 0.22 (Zwald et al., 2004; Neuenschwander et al., 2012; Parker-Gaddis et al., 2014). The posterior mean of genetic correlation between infectious lesions and lameness is $0.51(95 \%$ HPD: -0.098 ; 0.996), and genetic correlation between noninfectious lesions and lameness is 0.91 (95\% HPD: $0.636 ; 1.000)$. The posterior mean of genomic correlation between infectious lesions and lameness is 0.44 (95\% HPD: $-0.048,0.931)$ and genomic correlation between noninfectious lesions and lameness is $0.74(95 \%$ HPD: $0.305,0.994)$. In this study, in both pedigree- and genomic-based analysis, the genetic correlation between noninfectious lesions and lameness did not include zero in the 95\% HPD interval (Table 4). This indicates that most of the producer-recorded data in lameness trait were mainly noninfectious hoof lesions. The reason for

Table 4. Posterior mean, SD, and 95\% highest posterior density (HPD) of heritability and genetic correlation from bivariate analysis of hoof lesions and lameness traits from both pedigree- and genomic-based analysis

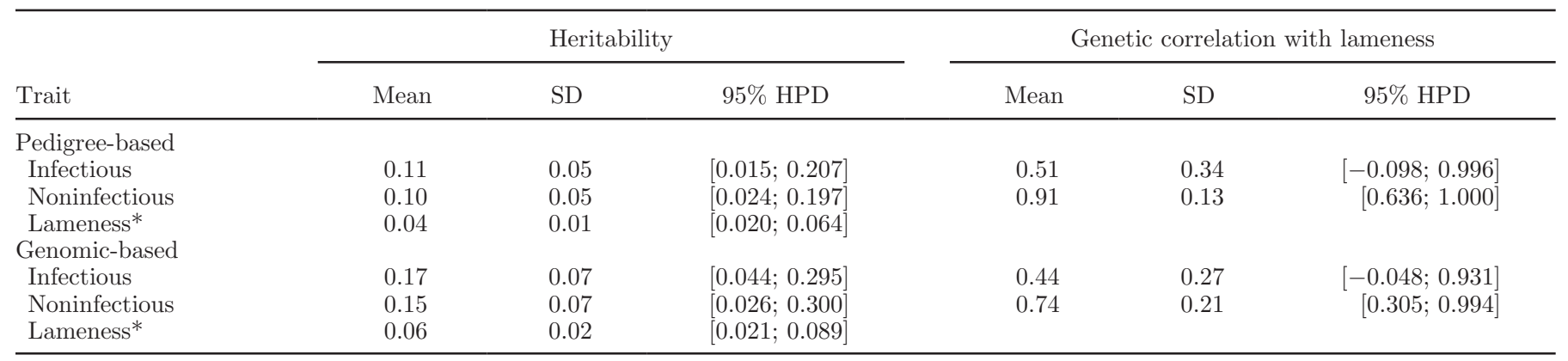

*Heritability of lameness reported from infectious-lameness bivariate analysis. 
this could be that because producers voluntarily record these records, there may be some bias in recording infectious hoof lesions.

The heritability estimates obtained for infectious and noninfectious hoof lesions in this study indicate that genetic or genomic selection is possible due to the presence of a heritable component in producer-recorded hoof lesions. Nordic countries have already included hoof health in their index and have seen slow progress in reducing prevalence of lameness. van der Linde et al. (2010) reported that when using a claw health index, the reduction in prevalence of lameness was 0.1 to $0.7 \%$ per year. Thus, genetic or genomic selection for hoof lesions should be incorporated into breeding programs to enable reasonable genetic improvement of cows' resistance to hoof lesions.

\section{REFERENCES}

Aguilar, I., I. Misztal, D. Johnson, A. Legarra, S. Tsuruta, and T. Lawlor. 2010. Hot topic: A unified approach to utilize phenotypic, full pedigree, and genomic information for genetic evaluation of Holstein final score. J. Dairy Sci. 93:743-752.

Aguilar, I., I. Misztal, A. Legarra, and S. Tsuruta. 2011. Efficient computation of the genomic relationship matrix and other matrices used in single-step evaluation. J. Anim. Breed. Genet. 128:422428.

Bicalho, R. C., and G. Oikonomou. 2013. Control and prevention of lameness associated with claw lesions in dairy cows. Livest. Sci. 156:96-105.

Buch, L. H., A. C. Sørensen, J. Lassen, P. Berg, J. Å. Eriksson, J. H. Jakobsen, and M. K. Sørensen. 2011. Hygiene-related and feed related hoof diseases show different patterns of genetic correlations to clinical mastitis and female fertility. J. Dairy Sci. 94:1540-1551.

Calo, L. L., R. E. McDowell, L. D. Van Vleck, and P. D. Miller. 1973. Genetic aspects of beef production among Holstein-Friesians pedigree selected for milk production. J. Anim. Sci. 37:676-682.

Campbell, M., and D. Machin. 1999. Medical Statistics: A Common Sense Approach. 3rd ed. Wiley, Chichester, UK.

Chapinal, N., A. Koeck, A. Sewalem, D. Kelton, S. Mason, G. Cramer, and F. Miglior. 2013. Genetic parameters for hoof lesions and their relationship with feet and leg traits in Canadian Holstein cows. J. Dairy Sci. 96:2596-2604.

Cole, J., and P. VanRaden. 2010. Net merit as a measure of lifetime profit: 2010 revision. United States Department of Agriculture, Animal Improvements Program Laboratory, Beltsville, MD.

Gernand, E., D. Döhne, and S. König. 2013. Genetic background of claw disorders in the course of lactation and their relationships with type traits. J. Anim. Breed. Genet. 130:435-444.

Guard, C. 1999. Control programs for digital dermatitis: The tools for success in the new millennium. Pages 235-242 in Advances in Dairy Technology. Vol. II. J. Kennelly, ed. University of Alberta, Edmonton, Canada.

Hayes, B. J., P. J. Bowman, A. J. Chamberlain, and M. E. Goddard. 2009. Invited review: Genomic selection in dairy cattle: Progress and challenges. J. Dairy Sci. 92:433-443.

Hernandez, J. A., E. J. Garbarino, J. K. Shearer, C. A. Risco, and W. W. Thatcher. 2005. Comparison of milk yield in dairy cows with different degrees of lameness. J. Am. Vet. Med. Assoc. 227:12921296.

Holzhauer, M., C. Hardenberg, C. Bartels, and K. Frankena. 2006. Herd-and cow-level prevalence of digital dermatitis in the Netherlands and associated risk factors. J. Dairy Sci. 89:580-588.
Johansson, K., J. Å. Eriksson, U. S. Nielsen, J. Pösö, and G. P. Aamand. 2011. Genetic evaluation of claw health in Denmark. Finland and Sweden. Interbull Bull. 44:224-228.

Legarra, A., and V. Ducrocq. 2012. Computational strategies for national integration of phenotypic, genomic, and pedigree data in a single-step best linear unbiased prediction. J. Dairy Sci. 95:46294645 .

Misztal, I., S. Tsuruta, I. Aguilar, A. Legarra, P. VanRaden, and T. Lawlor. 2013. Methods to approximate reliabilities in single-step genomic evaluation. J. Dairy Sci. 96:647-654.

Misztal, I., S. Tsuruta, T. Strabel, B. Auvray, T. Druet, and D. Lee. 2002. BLUPF90 and related programs (BGF90). Pages $1-2$ in Proc. 7th World Congr. Genet. Appl. Livest. Prod., Montpellier, France. Session 28. Institut National de la Recherche Agronomique (INRA), Paris, France.

Neuenschwander, T. F., F. Miglior, J. Jamrozik, O. Berke, D. Kelton, and L. Schaeffer. 2012. Genetic parameters for producer-recorded health data in Canadian Holstein cattle. Animal 6:571-578.

Oberbauer, A. M., S. Berry, J. Belanger, R. McGoldrick, J. PinosRodriquez, and T. Famula. 2013. Determining the heritable component of dairy cattle foot lesions. J. Dairy Sci. 96:605-613.

Ødegård, C., M. Svendsen, and B. Heringstad. 2014. Genetic correlations between claw health and feet and leg conformation in Norwegian Red cows. J. Dairy Sci. 97:4522-4529.

Parker Gaddis, K. L., J. Cole, J. Clay, and C. Maltecca. 2012. Incidence validation and relationship analysis of producer-recorded health event data from on-farm computer systems in the United States. J. Dairy Sci. 95:5422-5435.

Parker Gaddis, K. L., J. B. Cole, J. S. Clay, and C. Maltecca. 2014. Genomic selection for producer-recorded health event data in US dairy cattle. J. Dairy Sci. 97:3190-3199.

Plummer, M., N. Best, K. Cowles, K. Vines, D. Sarkar, and R. Almond. 2013. Package 'coda'. Accessed Jan. 12, 2014. http://cran.rproject.org/web/packages/coda/coda.pdf.

Somers, J. G., K. Frankena, E. N. Noordhuizen-Stassen, and J. Metz. 2003. Prevalence of claw disorders in dutch dairy cows exposed to several floor systems. J. Dairy Sci. 86:2082-2093.

Tsuruta, S., and I. Misztal. 2006. THRGIBBS1F90 for estimation of variance components with threshold and linear models. Pages 27-31 in Proc. 8th World Congr. Genet. Appl. Livest. Prod., Belo Horizonte, Minas Gerais, Brazil. Instituto Prociência, Belo Horizonte, Brazil.

van der Linde, C., G. De Jong, E. Koenen, and H. Eding. 2010. Claw health index for Dutch dairy cattle based on claw trimming and conformation data. J. Dairy Sci. 93:4883-4891.

VanRaden, P. M. 2008. Efficient methods to compute genomic predictions. J. Dairy Sci. 91:4414-4423.

VanRaden, P. M., C. P. Van Tassell, G. R. Wiggans, T. S. Sonstegard, R. D. Schnabel, J. F. Taylor, and F. Schenkel. 2009. Invited review: Reliability of genomic predictions for North American Holstein bulls. J. Dairy Sci. 92:16-24.

Vermunt, J. J. 2007. One step closer to unravelling the pathophysiology of claw horn disruption: For the sake of the cows' welfare. Vet. J. $174: 219-220$

von Keyserlingk, M., J. Rushen, A. M. de Passillé, and D. M. Weary. 2009. Invited review: The welfare of dairy cattle - Key concepts and the role of science. J. Dairy Sci. 92:4101-4111.

Wells, S. J., A. M. Trent, W. E. Marsh, and R. A. Robinson. 1993 Prevalence and severity of lameness in lactating dairy cows in a sample of Minnesota and Wisconsin herds. J. Am. Vet. Med. Assoc. $202: 78-82$.

Zwald, N. R, K. Weigel, Y. Chang, R. Welper, and J. Clay. 2004. Genetic selection for health traits using producer-recorded data. I. Incidence rates, heritability estimates, and sire breeding values. J. Dairy Sci. 87:4287-4294. 